\title{
ERRATUM
}

1. Dosage error in the article Figure 3 and Figure 4

Fig. 3: Specific proportion of crop land (sown areas) by types of farming entities, \%

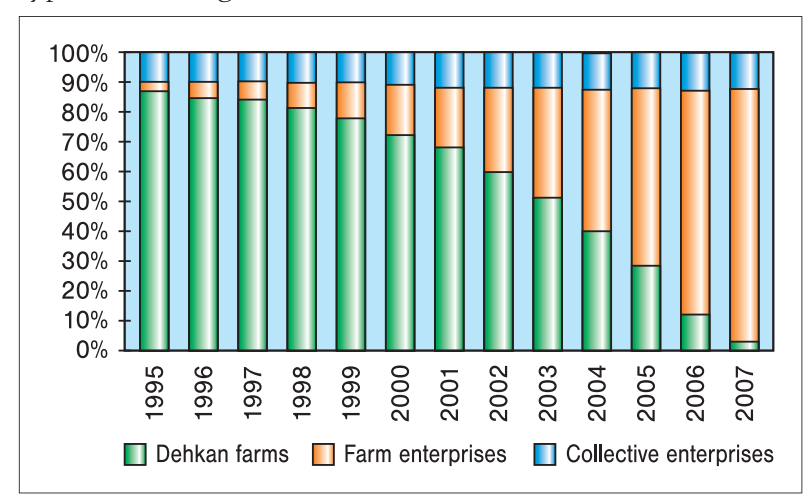

Fig. 4: The agricultural output in value terms by types of farming entities, \%

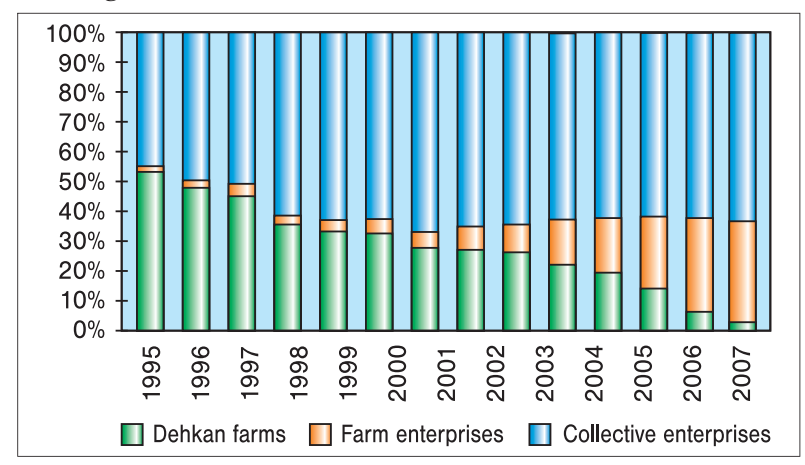

2. In EU agrarian Law. Analysis of the agrarian land reform in Uzbekistan during the soviet era and after transition. Volume 3, Issue 2, Pages 61-67, ISSN (Online) 1338-6891, DOI: 10.2478/eual-2014-0009, February 2015.

3. Description of the changes made.

The mistake happened when the person responsible for papers format redrawn two figures from the paper to comply with standards given by De Gruyter. He accidentally changed the „legend" of the figures particularly the legend "collective entreprises" with the legend "dehkan farms" by what he gave to it a completely different meaning basically denying everything stated in the paper.

\section{The change itself}

Fig. 3: Specific proportion of crop land (sown areas) by types of farming entities, \%

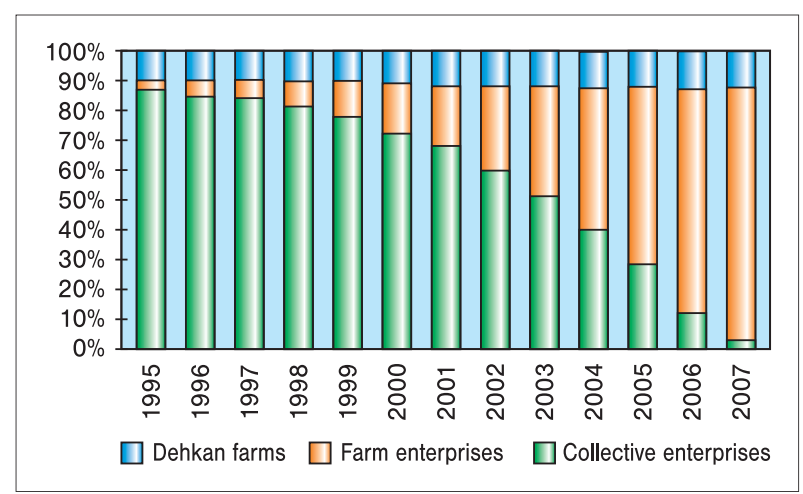

Fig. 4: The agricultural output in value terms by types of farming entities, \%

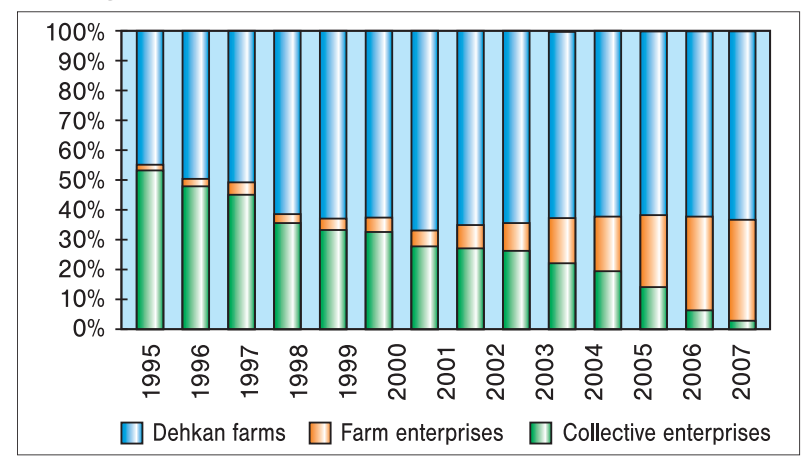

Source: The State Statistics Committee in Yusupov et al, 2010. Page 31

5. Listing of the Erratum DOI: 10.2478/eual-2014-0009 